\title{
SIFAT-SIFAT FUNGSI EKSPONENSIAL BERBASIS BILANGAN NATURAL YANG DIDEFINISIKAN SEBAGAI LIMIT
}

\author{
ENIVA RAMADANI \\ Program Studi Matematika, \\ Fakultas Matematika dan Ilmu Pengetahuan Alam, Universitas Andalas, \\ Kampus UNAND Limau Manis Padang, Indonesia. \\ DeNiva04@gmail.com
}

\begin{abstract}
Abstrak. Penelitian ini membahas tentang bagaimana sifat-sifat dari fungsi eksponensial yang berbasis bilangan natural, yang dinotasikan dengan $f(x)=e^{x}=\exp (x)$, serta dapat didefinisikan sebagai suatu limit dari dua fungsi yang berbeda, yaitu

$$
\exp (x)=\lim _{n \rightarrow \infty}\left(1+\frac{x}{n}\right)^{n} \text { atau } \exp (x)=\lim _{n \rightarrow \infty}\left(1-\frac{x}{n}\right)^{-n} .
$$
\end{abstract}

Kata Kunci: Fungsi Kontinu Seragam, Barisan, dan Limit Barisan

\section{Pendahuluan}

Bilangan $e$ adalah suatu bilangan riil positif yang bersifat $\ln e=1$. Bilangan $e$ merupakan bilangan natural, dan terkadang disebut sebagai bilangan Euler sebagai penghargaan atas ahli matematika Swiss, Leonhard Euler. Seperti bilangan $\pi$, bilangan $e$ adalah bilangan tak rasional. Pada Tahun 1748, Euler memberikan ide bahwa bilangan $e$ adalah

$$
e=1+\frac{1}{1 !}+\frac{1}{2 !}+\frac{1}{3 !}+\cdots+\frac{1}{n !}+\cdots .
$$

Dari [3], misalkan $a$ adalah suatu bilangan riil positif, $a \neq 1$. Suatu fungsi $f$ dikatakan fungsi eksponensial berbasis a jika memiliki kondisi berikut.

$$
f(x)=a^{x},
$$

dan biasanya dikenal dengan fungsi eksponen umum. Dalam kajian ini penulis membahas fungsi eksponensial untuk $a=e$ yang dinotasikan dengan

$$
e^{x}=\exp (x)
$$

Fungsi eksponensial berbasis $e$ dapat didefinisikan sebagai berikut

$$
\lim _{n \rightarrow \infty}\left(1+\frac{x}{n}\right)^{n}=\exp (x) .
$$

Dilain hal, fungsi eksponensial juga dapat didefinisikan dengan

$$
\exp (x)=\lim _{n \rightarrow \infty}\left(1-\frac{x}{n}\right)^{-n}
$$


Fungsi eksponensial yang berbasis $e$ sangatlah unik, karena dapat didefinisikan sebagai suatu limit dari dua buah fungsi yang berbeda, yaitu pada persamaan (1.1) dan persamaan (1.2). Oleh karena itu, penulis tertarik untuk mengkaji sifat-sifat dari fungsi eksponensial yang berbasis $e$ yang dapat didefinisikan sebagai limit dari dua buah fungsi yang berbeda.

\section{Landasan teori}

\subsection{Himpunan dan Fungsi}

Suatu himpunan di dalam $\mathbb{R}$ dikatakan terbatas dia atas jika himpunan tersebut mempunyai batas atas, dan dikatakan terbatas dibawah jika himpunan tersebut mempunyai batas bawah. Jika Suatu himpunan dalam $\mathbb{R}$ mempunyai batas atas dan batas bawah maka dikatakan himpunan tersebut terbatas.

Misalkan $A$ dan $B$ adalah dua himpunan tak kosong, $f$ dikatakan fungsi dari $A$ ke $B$ jika setiap unsur di $A$ dipetakan secara tunggal ke suatu unsur di $B$, ditulis sebagai $f: A \rightarrow B$.

Definisi 2.1. [1] Misalkan $A \subseteq \mathbb{R}$ dan $f: A \rightarrow \mathbb{R}$. Fungsi $f$ dikatakan kontinu seragam pada $A$ jika untuk setiap $\varepsilon>0$, terdapat $\delta(\varepsilon)>0$ sedemikian sehingga jika $x$ dan $u$ adalah sebarang titik di A yang memenuhi $|x-u|<\delta(\varepsilon)$, maka $|f(x)-f(u)|<\varepsilon$.

\subsection{Barisan dan Limit Barisan}

Barisan yang mempunyai suatu limit dinamakan barisan konvergen dan barisan yang tidak mempunyai limit dinamakan barisan divergen.

Definisi 2.2. [1] Misalkan $X=\left(x_{n}\right)$ adalah barisan bilangan riil. Bilangan $x \in \mathbb{R}$ dikatakan limit dari $\left(x_{n}\right)$ jika untuk setiap $\varepsilon>0$ terdapat suatu bilangan $K(\varepsilon) \in \mathbb{N}$ sedemikian sehingga untuk setiap $n \geq K(\varepsilon)$, suku ke $n$ berada dalam lingkungan $\varepsilon$ dari $x$, yaitu $x_{n} \in V_{\varepsilon}(x)$.

Definisi 2.3. [1] Suatu barisan riil $X=\left(x_{n}\right)$ dikatakan terbatas jika terdapat suatu bilangan $M \in \mathbb{R}$ dengan $M>0$, sedemikian sehingga $\left|x_{n}\right| \leq M$ untuk setiap $n \in \mathbb{N}$.

Definisi 2.4. [1] Barisan $X=\left(x_{n}\right)$ dikatakan naik (increasing), jika memenuhi ketaksamaan

$$
x_{1} \leq x_{2} \leq \cdots \leq x_{n} \leq x_{n+1} \leq \cdots,
$$

dan dikatakan turun (decreasing) jika memenuhi

$$
x_{1} \geq x_{2} \geq \cdots \geq x_{n} \geq x_{n+1} \geq \cdots .
$$

Barisan $X$ dikatakan monoton jika barisan tersebut naik atau turun. Bila suatu barisan memenuhi

$$
x_{1}<x_{2}<\cdots<x_{n}<x_{n+1}<\cdots \text { atau } x_{1}>x_{2}>\cdots>x_{n}>x_{n+1}>\cdots,
$$

maka berturut-turut dinamakan barisan naik sejati atau turun sejati. 
Teorema 2.5. [1] Misalkan $X=\left(x_{n}\right)$ adalah barisan monoton. Barisan $X=x_{n}$ konvergen jika dan hanya jika $\left(x_{n}\right)$ terbatas. Selanjutnya:

(1) Jika barisan $X=\left(x_{n}\right)$ naik terbatas, maka $\lim \left(x_{n}\right)=\sup \left\{x_{n}\right\}$.

(2) Jika barisan $Y=\left(y_{n}\right)$ turun terbatas, maka $\lim \left(y_{n}\right)=\inf \left\{y_{n}\right\}$.

\subsection{Fungsi Floor}

Definisi 2.6. [2] Misalkan $x$ adalah suatu bilangan riil sebarang. Dapat didefinisikan

$$
\begin{aligned}
& \lfloor x\rfloor=\text { bilangan bulat terbesar yang kurang dari atau sama dengan } x, \\
& \lceil x\rceil=\text { bilangan bulat terkecil yang lebih dari atau sama dengan } x \text {. }
\end{aligned}
$$

Bilangan $\lfloor x\rfloor$ dinamakan floor dari $x$ dan $\lceil x\rceil$ dinamakan ceiling dari $x$.

\subsection{Induksi Matematika}

Aksioma 2.7. [4] Misalkan $P(n)$ adalah suatu proposisi perihal bilangan asli, jika

(1) $P(1)$ benar, dan

(2) untuk setiap $k \geq 2$, berlaku $(P(n=k-1) \rightarrow P(n=k))$, maka $P(n)$ benar untuk semua $n \in \mathbb{N}^{+}$.

Proposisi 2.8. [5] Untuk sebarang bilangan non-negatif $a_{1}, a_{2}, \cdots, a_{n}, a_{n+1}$ berlaku

$$
\frac{a_{1}+a_{2}+\cdots+a_{n}+a_{n+1}}{n+1} \geq \sqrt[n+1]{a_{1} a_{2} \cdots a_{n+1}},
$$

dan bernilai sama jika dan hanya jika $a_{1}=a_{2}=\cdots=a_{n}=a_{n+1}$.

\section{Pembahasan}

Misalkan $x \in \mathbb{R}$, dan misalkan bilangan $m_{0}=m_{0}(x)$ dan $n_{0}=n_{0}(x)$ didefinisikan sebagai berikut:

$$
m_{0}=m_{0}(x)=\min \{k \in \mathbb{N} \mid k>x\} \text { dan } n_{0}=n_{0}(x)=\min \{k \in \mathbb{N} \mid k>-x\} .
$$

Jadi, $m_{0}=1$ dan $n_{0}=\lfloor-x\rfloor+1$ jika $x \leq 0$, dan $m_{0}=\lfloor x\rfloor+1$ dan $n_{0}=1$ jika $x \geq 0$. Jelas bahwa, $1+\frac{x}{n}>0$ untuk sebarang $n \geq n_{0}$, dan $1-\frac{x}{n}>0$ untuk sebarang $n \geq m_{0}$.

Lema 3.1. [5] Misalkan $x \in \mathbb{R}$ dan definisikan barisan $f_{n}(x)$ dan $g_{n}(x)$ sebagai berikut:

$$
\begin{aligned}
& f_{n}(x)=\left\{\begin{array}{ll}
0, & n<n_{0}, \\
\left(1+\frac{x}{n}\right)^{n}, & n \geq n_{0}
\end{array}\right. \text { dan } \\
& g_{n}(x)= \begin{cases}0, & n<m_{0} \\
\left(1-\frac{x}{n}\right)^{-n} & , n \geq m_{0}\end{cases}
\end{aligned}
$$

Maka 
(a) Barisan $\left(f_{n}(x)\right)$ adalah naik untuk $n \geq n_{0}$, yaitu $f_{n}(x) \leq f_{n+1}(x), \forall n \geq n_{0}$. Khususnya, $\left(f_{n}(x)\right)$ adalah naik untuk $x \geq 0$ karena $n_{0}=1$.

(b) Barisan $\left(g_{n}(x)\right)$ adalah turun untuk $n \geq m_{0}$, yaitu $g_{n}(x) \geq g_{n+1}(x), \forall n \geq m_{0}$. Khususnya, $\left(g_{n}(x)\right)$ adalah turun untuk $x \leq 0$ karena $m_{0}=1$.

(c) $0 \leq g_{n}(x) \leq-f_{n}(x) \leq \frac{x^{2}}{n} g_{k_{0}}$ untuk sebarang $n \geq k_{0}=\max \left\{m_{0}, n_{0}\right\}$.

(d) Terdapat

$$
\begin{aligned}
& \lim _{n \rightarrow \infty} f_{n}(x)=\sup \left\{f_{n}(x) \mid n \in \mathbb{N}\right\}, \text { dan } \\
& \lim _{n \rightarrow \infty} g_{n}(x)=\lim _{n \rightarrow \infty} f_{n}(x)=L .
\end{aligned}
$$

Lebih jauh, $f_{n_{0}}(x) \leq L \leq g_{m_{0}}(x)$.

(e) Jika $|h|<1$ maka

$$
1+h \leq\left(1+\frac{h}{n}\right)^{n} \leq\left(1-\frac{h}{n}\right)^{-n} \leq(1-h)^{-1} \text { untuk semua } n \geq 1 .
$$

\section{Bukti.}

(a) Misalkan $n \geq n_{0}$ dan $a_{1}=1, a_{2}=a_{3}=\cdots=a_{n+1}=1+\frac{x}{n}>0$. Perhatikan bahwa:

$$
\begin{aligned}
1+\frac{x}{n+1} & =\frac{(n+1)+x}{n+1} \\
& =\frac{1+n\left(1+\frac{x}{n}\right)}{n+1} \\
& =\frac{1+\left(1+\frac{x}{n}\right)+\left(1+\frac{x}{n}\right)+\cdots+\left(1+\frac{x}{n}\right)}{n+1} \\
& \geq \sqrt[n+1]{1\left(1+\frac{x}{n}\right)\left(1+\frac{x}{n}\right) \cdots\left(1+\frac{x}{n}\right)} \\
& =\sqrt[n+1]{\left(1+\frac{x}{n}\right)^{n}}
\end{aligned}
$$

Jadi, barisan $\left(f_{n}(x)\right)$ adalah naik karena

$$
f_{n+1}(x)=\left(1+\frac{x}{n+1}\right)^{n+1} \geq\left(1+\frac{x}{n}\right)^{n}=f_{n}(x) .
$$

Pertaksamaan ini juga terpenuhi untuk $x=0$.

(b) Misalkan $n \geq m_{0}$ dan $a_{1}=1, a_{2}=a_{3}=\cdots=a_{n+1}=1-\frac{x}{n}>0$. Perhatikan bahwa:

$$
\begin{aligned}
1-\frac{x}{n+1} & =\frac{(n+1)-x}{n+1}, \\
& =\frac{1+n\left(1-\frac{x}{n}\right)}{n+1} \\
& =\frac{1+\left(1-\frac{x}{n}\right)+\left(1-\frac{x}{n}\right)+\cdots+\left(1-\frac{x}{n}\right)}{n+1} \\
& \left.\geq \sqrt[n+1]{1\left(1-\frac{x}{n}\right)\left(1-\frac{x}{n}\right) \cdots\left(1-\frac{x}{n}\right)} \quad \text { (dari Pertaksamaan }(2.1)\right) \\
& =\sqrt[n+1]{\left(1-\frac{x}{n}\right)^{n}} .
\end{aligned}
$$


Akibatnya

$$
\left(1-\frac{x}{n+1}\right)^{n+1} \geq\left(1-\frac{x}{n}\right)^{n}>0 .
$$

Jadi, barisan $\left(g_{n}(x)\right)$ adalah turun karena

$$
g_{n+1}(x)=\left(1-\frac{x}{n+1}\right)^{-(n+1)} \leq\left(1-\frac{x}{n}\right)^{-n}=g_{n}(x)
$$

Pertaksamaan ini juga terpenuhi untuk $x=0$.

(c) Misalkan $n \geq k_{0}=\max \left\{m_{0}, n_{0}\right\}$.

Perhatikan bahwa:

$$
\begin{aligned}
g_{n}(x)-f_{n}(x) & =g_{n}(x)-\frac{g_{n}(x)}{g_{n}(x)} f_{n}(x) \\
& =g_{n}(x)\left(1-\frac{f_{n}(x)}{g_{n}(x)}\right) \\
& =g_{n}(x)\left(1-\frac{\left(1+\frac{x}{n}\right)^{n}}{\left(1-\frac{x}{n}\right)^{-n}}\right) \\
& =g_{n}(x)\left(1-\left\{\frac{(n+x)^{n}}{n^{n}} \frac{n^{-n}}{(n-x)^{-n}}\right\}\right) \\
& =g_{n}(x)\left(1-\frac{\left(n^{2}-x^{2}\right)^{n}}{\left(n^{2}\right)^{n}}\right) \\
& =g_{n}(x)\left(1-\left(\frac{n^{2}}{n^{2}}-\frac{x^{2}}{n^{2}}\right)^{n}\right) \\
& =g_{n}(x)\left(1-\left(1-\frac{x^{2}}{n^{2}}\right)^{n}\right) \\
& =g_{n}(x)\left(1-q^{n}\right)
\end{aligned}
$$

dimana $q=1-\frac{x^{2}}{n^{2}}$.

Selanjutnya akan dibuktikan bahwa $n \geq k_{0}>|x|$. Misalkan $n \geq k_{0}=$ $\max \left\{m_{0}, n_{0}\right\}$.

(1) Kasus 1. Untuk $x \leq 0$.

Diperoleh $n \geq k_{0}=\max \{1,\lfloor-x\rfloor+1\}=\lfloor-x\rfloor+1>-x$. Jadi $x>-k_{0}$.

(2) Kasus 2. Untuk $x \geq 0$.

Diperoleh $n \geq k_{0}=\max \{\lfloor x\rfloor+1,1\}=\lfloor x\rfloor+1>x$. Jadi $x<k_{0}$.

Dari Kasus 1 dan Kasus 2 dapat disimpulkan bahwa $n \geq k_{0}>|x|$. Karena $0 \leq \frac{x^{2}}{n^{2}}<1$ maka $q=1-\frac{x^{2}}{n^{2}} \leq 1$. Akibatnya $0<q \leq 1$, sehingga

$$
\begin{aligned}
q \leq 1 & \Leftrightarrow q^{n} \leq 1 \\
& \Leftrightarrow 1-q^{n} \geq 0 .
\end{aligned}
$$

Jelas bahwa, $g_{n}(x)-f_{n}(x) \geq 0$ untuk $n \geq k_{0}$. 
Perhatikan bahwa

$$
\begin{aligned}
0 \leq g_{n}(x)-f_{n}(x) & =g_{n}(x)\left(1-q^{n}\right) \\
& =g_{n}(x)(1-q)\left(1+q+q^{2}+\cdots+q^{n-1}\right) \\
& =g_{n}(x) \frac{x^{2}}{n^{2}}\left(1+q^{2}+\cdots+q^{n-1}\right) \\
& \leq g_{k_{0}}(x) \frac{x^{2}}{n^{2}}(1+1+\cdots+1) \\
& =\frac{x^{2}}{n} g_{k_{0}}(x) .
\end{aligned}
$$

Sehingga dapat disimpulkan bahwa

$$
0 \leq g_{n}(x)-f_{n}(x) \leq \frac{x^{2}}{n} g_{k_{0}}(x) \text { untuk } n \geq k_{0}
$$

Dari Pertaksamaam (3.2), misal diberikan $\varepsilon>0$, jika dipilih suatu bilangan asli $N>\frac{x^{2} g_{k_{0}}(x)}{\varepsilon}$ dengan $N \geq k_{0}$ maka

$$
\left|g_{n}(x)-f_{n}(x)-0\right|=g_{n}(x)-f_{n}(x) \leq \frac{x^{2}}{n} g_{k_{0}}<\varepsilon \text { untuk } n>N .
$$

Ini menunjukkan bahwa

$$
\lim _{n \rightarrow \infty}\left(g_{n}(x)-f_{n}(x)\right)=0 .
$$

(d) Misalkan $k_{0}=\max \left\{m_{0}, n_{0}\right\} \geq m_{0}$. Berdasarkan sifat (b) dan (c), maka

(i) $g_{n}(x) \leq g_{k_{0}}(x)$

(ii) Untuk semua $n \geq k_{0}$,

$$
\begin{aligned}
g_{n}(x)-f_{n}(x) & \geq 0 \quad(\text { dari Pertaksamaan }(3.2) \\
f_{n}(x) & \leq g_{n}(x) \leq g_{k_{0}}(x) .
\end{aligned}
$$

Ini menunjukkan bahwa barisan $\left(f_{n}(x)\right)$ terbatas di atas untuk setiap $x \in \mathbb{R}$ dan $\lim _{n \rightarrow \infty} f_{n}(x)=L, \operatorname{dimana} L=\sup \left\{f_{n}(x) \mid n \in \mathbb{N}\right\}=\sup \left\{f_{n}(x) \mid n \geq n_{0}\right\}$. Perhatikan bahwa

$$
\begin{aligned}
\lim _{n \rightarrow \infty} g_{n}(x) & =\lim _{n \rightarrow \infty}\left(\left(g_{n}(x)-f_{n}(x)\right)+f_{n}(x)\right) \\
& =\lim _{n \rightarrow \infty}\left(g_{n}(x)-f_{n}(x)\right)+\lim _{n \rightarrow \infty} f_{n}(x) \\
& =0+L \quad \text { (dari Persamaan }(? ?) \\
& =L .
\end{aligned}
$$

Jadi $\lim _{n \rightarrow \infty} f_{n}(x)=\lim _{n \rightarrow \infty} g_{n}(x)=L$.

(e) Misalkan $|h|<1$, pertama akan ditunjukkan $m_{0}=n_{0}=1$.

Perhatikan dua kasus berikut:

(i) Untuk $-1<h \leq 0$, maka $m_{0}=1$ dan $n_{0}=[-h]+1$. Karena $h$ tidak pernah mencapai nilai -1 , maka $[-h]=0$. Akibatnya $m_{0}=n_{0}=1$.

(ii) Untuk $0 \leq h<1$, maka $n_{0}=1$ dan $m_{0}=[h]+1$.Karena $h$ tidak pernah mencapai nilai 1 , maka $[h]=0$. Akibatnya $m_{0}=n_{0}=1$. 
Dari (i) dan (ii) menunjukkan bahwa $m_{0}=n_{0}=1$, serta dari (a), (b), dan (c) diperoleh

$$
1+h=f_{1}(h) \leq f_{n}(h) \leq g_{n}(h) \leq g_{1}(h)=(1-h)^{-1} \text { untuk sebarang } n \geq 1 .
$$

Dari Lemma 3.1 telah dibuktikan eksistensi dan kesamaan dari kedua limit yaitu $\lim _{n \rightarrow \infty}\left(1+\frac{x}{n}\right)^{n}=\lim _{n \rightarrow \infty}\left(1-\frac{x}{n}\right)^{-n}$ untuk setiap $x \in \mathbb{R}$. Jadi fungsi eksponensial $: \mathbb{R} \rightarrow(0, \infty)$ dapat ditulis sebagai berikut:

$$
\exp (x)=\lim _{n \rightarrow \infty}\left(1+\frac{x}{n}\right)^{n}=\lim _{n \rightarrow \infty}\left(1-\frac{x}{n}\right)^{-n}, x \in \mathbb{R} .
$$

Jelas bahwa $\exp (0)=1$. Nilai dari $\exp (1)$ adalah suatu bentuk khusus yang disebut bilangan $e$, yang didefinisikan sebagai berikut

$$
e=\lim _{n \rightarrow \infty}\left(1+\frac{1}{n}\right)^{n} \approx 2.71828182846 .
$$

Fungsi yang didefinisikan oleh (3.5) disebut dengan fungsi eksponensial berbasis $e$, dinotasikan dengan $e^{x}$. Berikut diberikan sifat-sifat dari fungsi eksponensial.

Proposisi 3.2. [5] Misalkan $x \in \mathbb{R}$.

(i) Jika $x>-1$ maka $\exp (x)>1+x$. Khususnya, $\exp (x)>1$ untuk $x>0$.

(ii) Jika $x<1$ maka $\exp (x) \leq \frac{1}{1-x}$. Khususnya, $\exp (x)<1$ jika $x<0$.

Bukti. Misalkan $x \in \mathbb{R}$.

(i) Jika $x>-1$ maka $n_{0}=\lfloor-x\rfloor+1=1$. Berdasarkan Lemma 3.1 (a) dan (d), diperoleh

$$
\exp (x) \geq\left(1+\frac{x}{2}\right)^{2}>\left(1+\frac{x}{1}\right)^{1}=1+x .
$$

(ii) Jika $x<1$ maka $m_{0}=\lfloor x\rfloor+1=1$. Bedasarkan Lemma 3.1 (c), diperoleh $f_{n}(x) \leq g_{n}(x)$ untuk setiap $n \geq k_{0}=\max \left\{m_{0}, n_{0}\right\}$. Berdasarkan Lemma 3.1 (b), maka $f_{n}(x) \leq g_{n}(x) \leq g_{1}(x)$. Jika untuk $n \rightarrow \infty$, maka berdasarkan Lemma 3.1 (d) diperoleh

$$
\begin{aligned}
\lim _{n \rightarrow \infty} f_{n}(x) & \leq g_{1}(x), \\
& =\left(1-\frac{x}{1}\right)^{-1} \\
& =\frac{1}{1-x} .
\end{aligned}
$$

Proposisi 3.3. [5] Untuk sebarang $x, y \in \mathbb{R}$ berlaku

$$
\exp (x+y)=\exp (x) \exp (y)=\exp (y) \exp (x) .
$$

Khususnya

$$
\exp (-x)=(\exp (x))^{-1}=\frac{1}{\exp (x)} \text { untuk setiap } x \in \mathbb{R}
$$


Bukti. Misalkan barisan $\left(f_{n}(x)\right),\left(f_{n}(y)\right)$, dan $\left(f_{n}(x+y)\right)$ didefinisikan sebagai berikut:

$$
\begin{aligned}
f_{n}(x) & =\left(1+\frac{x}{n}\right)^{n}, \\
f_{n}(y) & =\left(1+\frac{y}{n}\right)^{n}, \text { dan } \\
f_{n}(x+y) & =\left(1+\frac{x+y}{n}\right)^{n},
\end{aligned}
$$

dimana $n \geq k_{0}>|x|+|y|$. Definisikan barisan $(h(n))$ sebagai berikut:

$$
h(n)=\frac{x y}{n+x+y} .
$$

Perhatikan bahwa

$$
\lim _{n \rightarrow \infty} h(n)=\lim _{n \rightarrow \infty} \frac{x y}{n+x+y}=0 .
$$

Jika dipilih bilangan yang cukup besar $N$, sehingga $|h(n)|<1$ untuk $n \geq N$. Perhatikan bahwa

$$
\begin{aligned}
\frac{f_{n}(x) f_{n}(y)}{f_{n}(x+y)} & =\frac{\left(1+\frac{x}{n}\right)^{n}\left(1+\frac{y}{n}\right)^{n}}{\left(1+\frac{x+y}{n}\right)^{n}} \\
& =\frac{(n+x)^{n}(n+y)^{n}}{n^{n}(n+x+y)^{n}} \\
& =\left(\frac{n^{2}+n x+n y+x y}{n^{2}+n x+n y}\right)^{n} \\
& =\left(1+\frac{h(n)}{n}\right)^{n} \text { untuk semua } n \geq N .
\end{aligned}
$$

Berdasarkan pertaksamaan (3.2) dan pertaksamaan (3.4) jelas bahwa

$$
1+h(n) \leq\left(1+\frac{h(n)}{n}\right)^{n}=\frac{f_{n}(x) f_{n}(y)}{f_{n}(x+y)} \leq(1-h(n))^{-1} .
$$

Perhatikan bahwa

$$
\begin{aligned}
\lim _{n \rightarrow \infty}(1+h(n)) & =\lim _{\substack{n \rightarrow \infty \\
\text { dan }}} 1+\lim _{n \rightarrow \infty} h(n)=1+0=1 \\
\lim _{n \rightarrow \infty}(1-h(n))^{-1} & =\lim _{n \rightarrow \infty} \frac{1}{1-h(n)}=1
\end{aligned}
$$

Karena $\lim _{n \rightarrow \infty}(1+h(n))=\lim _{n \rightarrow \infty}(1-h(n))^{-1}=1$, sehingga diperoleh:

$$
\lim _{n \rightarrow \infty} \frac{f_{n}(x) f_{n}(y)}{f_{n}(x+y)}=1
$$


Perhatikan bahwa

$$
\begin{aligned}
& \frac{\exp (x) \exp (y)}{\exp (x+y)}=\frac{\lim _{n \rightarrow \infty} f_{n}(x) \lim _{n \rightarrow \infty} f_{n}(y)}{\lim _{n \rightarrow \infty} f_{n}(x+y)} \\
& \frac{\exp (x) \exp (y)}{\exp (x+y)}=\lim _{n \rightarrow \infty} \frac{f_{n}(x) f_{n}(y)}{f_{n}(x+y)} \\
& \frac{\exp (x) \exp (y)}{\exp (x+y)}=1 \\
& \exp (x) \exp (y)=\exp (x+y) .
\end{aligned}
$$

Proposisi 3.4. [5] Misalkan $t, x \in \mathbb{R}$ jika $t<x$, maka $\exp (t)<\exp (x)$ dan fungsi ini naik sejati pada $\mathbb{R}$.

Bukti. Jika $x>t$ maka $x-t>0$ dan berdasarkan Lema $3.1(1)$, maka exp $(x-t)>$ 1. Perhatikan bahwa

$$
\begin{aligned}
\exp (x) & =\exp ((x-t)+t) \\
& =\exp (x-t) \exp (t)>1 \exp (t) \\
& =\exp (t)
\end{aligned}
$$

Sehingga diperoleh $\exp (t)<\exp (x)$.

Proposisi 3.5. [5] Jika $x>0$ maka $0<\exp (x)-1 \leq x \exp (x)$.

Bukti. Misalkan $n \in \mathbb{N}$, perhatikan bahwa

Akibatnya

$$
\begin{aligned}
0<\left(1+\frac{x}{n}\right)^{n}-1 & =\left(1+\frac{x}{n}-1\right)\left(\left(1+\frac{x}{n}\right)^{n-1}+\left(1+\frac{x}{n}\right)^{n-2}+\ldots+1\right) \\
& <\frac{x}{n}\left(\left(1+\frac{x}{n}\right)^{n}+\left(1+\frac{x}{n}\right)^{n}+\ldots+\left(1+\frac{x}{n}\right)^{n}\right) \\
& =\frac{x}{n} n\left(1+\frac{x}{n}\right)^{n}=x\left(1+\frac{x}{n}\right)^{n}<x \exp (x) .
\end{aligned}
$$

$$
0<\left(1+\frac{x}{n}\right)^{n}-1<x \exp (x) \text { untuk sebarang } n \in \mathbb{N} .
$$

Jika $n \rightarrow \infty$, pertaksamaan terakhir menjadi

$$
0<\exp (x)-1 \leq x \exp (x)
$$

Proposisi 3.6. [5] Fungsi eksponensial adalah fungsi kontinu pada $\mathbb{R}$, yaitu apabila diberikan suatu bilangan $a \in \mathbb{R}$ dan sebarang $\varepsilon>0$, maka dapat diperoleh suatu bilangan $\delta=\delta(\varepsilon, a)>0$ sedemikian sehingga jika $|x-a|<\delta$ maka $\mid \exp (x)-$ $\exp (a) \mid<\varepsilon$.

Bukti. Pertama-tama akan ditunjukkan bahwa pertaksamaan berikut berlaku.

$$
\exp (t)-1|\leq 3| t \mid \text { untuk }|t|<1 \text {. }
$$

(a) Kasus $t=0$, jelas bahwa pertaksamaan ini berlaku.

(b) Kasus $t \neq 0$ : 
(1) Jika $0<t<1$ maka $\exp (t)<\exp (1)=e<3$. Akibatnya, berdasarkan Pertaksamaan (3.7) diperoleh

$$
\begin{aligned}
& 0<\exp (t)-1 \leq t \exp (t) \\
& 0<\exp (t)-1<3 t .
\end{aligned}
$$

(2) Jika $-1<t<0$, maka berlaku Lema $3.1(1)$, yaitu $\exp (t)<1$. Dilain hal, $0<-t<1$ dan akibatnya

$$
0<\exp (-t)-1<3(-t)=3|t| .
$$

Perhatikan bahwa

$$
\begin{aligned}
|\exp (t)-1| & =\left|\exp (t)-\exp (t) \frac{1}{\exp (t)}\right| \\
& =\left|\exp (t)-\exp (t) \quad(\exp (t))^{-1}\right| \\
& =|\exp (t)-\exp (t) \quad \exp (-t)| \\
& =\mid \exp (t)(1-\exp (-t) \mid \\
& =|\exp (t)||1-\exp (-t)| \\
& =|\exp (t)||-(\exp (-t)-1)| \\
& =|\exp (t)||-1||(\exp (-t)-1)| \\
& =\exp (t) \quad 1 \quad(\exp (-t)-1) \\
& <\exp (t) 3|t|=3 \exp (t)|t|<3|t| .
\end{aligned}
$$

Pertaksamaan (3.8) telah terbukti. Misalkan $\varepsilon>0$ dan $a \in \mathbb{R}$. Perhatikan nilai dari $x$ dimana $|x-a|<1$. Pilih $t=x-a$ untuk Pertaksamaan (3.8) sehingga diperoleh:

$$
|\exp (t)-1|=|\exp (x-a)-1|<3 \quad|x-a| .
$$

Perhatikan bahwa

$$
\begin{aligned}
|\exp (x)-\exp (a)| & =|\exp (t+a)-\exp (a)| \\
& =|\exp (t) \exp (a)-\exp (a)| \quad \text { dari Pertaksamaan (3.6) } \\
& =|\exp (a)||\exp (t)-1| \\
& <\exp (a) 3|x-a|=3 \exp (a)|x-a| .
\end{aligned}
$$

Akibatnya, pilih

$$
\delta(\varepsilon)=\min \left\{1, \frac{\varepsilon}{3 \exp (a)}\right\}
$$

maka berlaku

$$
0<|x-a|<\delta(\varepsilon) \Rightarrow|\exp (x)-\exp (a)|=|\exp (t+a)-\exp (a)|<\varepsilon .
$$

Karena $\varepsilon>0$ sebarang, maka dapat disimpulkan bahwa $f(x)=\exp (x)$ kontinu seragam di $\mathbb{R}$. Hal ini juga menunjukkan bahwa $f(x)=\exp (x)$ kontinu di $\mathbb{R}$. 


\section{Kesimpulan}

Fungsi eksponensial yang berbasis $e$ dapat didefinisikan sebagai berikut

$$
\exp (x)=\lim _{n \rightarrow \infty}\left(1+\frac{x}{n}\right)^{n}=\lim _{n \rightarrow \infty}\left(1-\frac{x}{n}\right)^{-n}, x \in \mathbb{R},
$$

dan memiliki beberapa sifat, antara lain sebagai berikut:

(1) Misalkan $x \in \mathbb{R}$.

(i) Jika $x>-1$ maka $\exp (x)>1+x$. Khususnya, $\exp (x)>1$ untuk $x>0$.

(ii) Jika $x<1$ maka $\exp (x) \leq \frac{1}{1-x}$. Khususnya, $\exp (x)<1$ jika $x<0$.

(2) Sifat perkalian eksponensial, yaitu

$$
\exp (x+y)=\exp (x) \exp (y)=\exp (y) \exp (x) \text { untuk sebarang } x, y \in \mathbb{R} .
$$

Khususnya

$$
\exp (-x)=(\exp (x))^{-1}=\frac{1}{\exp (x)} \text { untuk setiap } x \in \mathbb{R} .
$$

(3) Misalkan $t, x \in \mathbb{R}$ dengan $t<x$, maka $\exp (t)<\exp (x)$ dan fungsi ini naik sejati pada $\mathbb{R}$.

(4) Jika $x>0$ maka $0<\exp (x)-1 \leq x \exp (x)$.

(5) Fungsi eksponensial adalah fungsi kontinu pada $\mathbb{R}$.

\section{Ucapan Terima kasih}

Penulis mengucapkan terima kasih kepada Bapak Dr. Dodi Devianto, Bapak Zulakmal, M.Si dan Ibu Dr. Yanita yang telah memberikan masukan dan saran dalam penyempurnaan penulisan artikel ini.

\section{Daftar Pustaka}

[1] Bartle, R.G. and D.R. Sherbert. 2000. Introduction to Real Analysis. New York: John Wiley and Sons

[2] Clark, W. Edwin. 2002. Elementary Number Theory. Florida: Department of Mathematics University of South Florida

[3] Finney, Ross L., Franklin D. Demana, Bert K. Waits, and Daniel Kennedy. 2000. Calculus: A Complete Course, Second Edition. Amerika: Addison Wesley Longman

[4] Morris, Dave Witte and Joy Morris. 2009. Proofs and Concepts the Fundamentals of Abstract Mathematics. New York: University at Albany

[5] Salas, Alvaro H. 2012. The exponential function as a limit. Applied Mathematical Sciences. 6: $4519-4526$ 